\title{
The Thymus Is a Common Target Organ in Infectious Diseases
}

\section{Wilson Savino}

\section{ABSTRACT}

I nfectious disease immunology has largely focused on the effector immune response, changes in the blood and peripheral lymphoid organs of infected individuals, and vaccine development. Studies of the thymus in infected individuals have been neglected, although this is progressively changing. The thymus is a primary lymphoid organ, able to generate mature $\mathrm{T}$ cells that eventually colonize secondary lymphoid organs, and is therefore essential for peripheral $\mathrm{T}$ cell renewal. Recent data show that normal thymocyte development and export can be altered as a result of an infectious disease. One common feature is the severe atrophy of the infected organ, mainly due to the apoptosis-related depletion of immature $\mathrm{CD} 4^{+} \mathrm{CD} 8^{+}$thymocytes. Additionally, thymocyte proliferation is frequently diminished. The microenvironmental compartment of the thymus is also affected, particularly in acute infectious diseases, with a densification of the epithelial network and an increase in the deposition of extracellular matrix. In the murine model of Chagas disease, intrathymic chemokine production is also enhanced, and thymocytes from Trypanosoma cruzi-infected mice exhibit greater numbers of cell migration-related receptors for chemokines and extracellular matrix, as well as increased migratory responses to the corresponding ligands. This profile is correlated with the appearance of potentially autoreactive thymus-derived immature $\mathrm{CD} 4^{+} \mathrm{CD} 8^{+} \mathrm{T}$ cells in peripheral organs of infected animals. A variety of infectious agents-including viruses, protozoa, and fungi-invade the thymus, raising the hypothesis of the generation of central immunological tolerance for at least some of the infectious agent-derived antigens. It seems clear that the thymus is targeted in a variety of infections, and that such targeting may have consequences on the behavior of peripheral $\mathrm{T}$ lymphocytes. In this context, thymus-centered immunotherapeutic approaches potentially represent a new tool for the treatment of severe infectious diseases.

\section{Introduction}

Immunology of infectious diseases has focused mainly on the effector immune response, changes in the blood and peripheral lymphoid organs of infected individuals, and vaccine development. In comparison, studies on the thymus under the biological pressure of an infectious agent have been few, although the large amount of data recently published on the thymus of HIV-bearing patients promises to improve this deficiency.

In the present review we will discuss a number of findings related to the lymphoid as well as the microenvironmental compartments of the thymus in the infectious disease state (including the thymic invasion by some infectious agents), as well as the phenotypic and functional changes seen with each of these intrathymic cellular compartments, comprising proliferation, death, secretion, migration, and differentiation. Selected examples of viral and parasitic infectious diseases will be discussed in more detail. Nevertheless, before compiling and discussing these data, it is worthwhile to provide a general background on the structure of the thymic microenvironment and its role in intrathymic $\mathrm{T}$ cell differentiation.

The thymic microenvironment and $\mathrm{T}$ cell differentiation. The thymus is a primary lymphoid organ in which bone marrow-derived $\mathrm{T}$ cell precursors undergo differentiation, ultimately leading to migration of positively selected thymocytes to the $\mathrm{T}$ cell-dependent areas of peripheral lymphoid organs. This process involves sequential expression of various proteins and rearrangements of $\mathrm{T}$ cell receptor (TCR) genes.

Along with differentiation, the most immature thymocytes express neither the TCR complex nor the CD4 or CD8 accessory molecules; they are called double-negative $\left(\mathrm{CD}^{-}{ }^{-} \mathrm{CD} 8^{-}\right)$cells and represent $5 \%$ of total thymocytes. Maturation progresses with the acquisition of CD4 and CD8 markers, generating $\mathrm{CD} 4^{+} \mathrm{CD} 8^{+}$double-positive cells, which constitute $80 \%$ of the whole population. At this stage, TCR genes are completely rearranged, and productive rearrangements yield the membrane expression of TCRs (complexed with CD3) at low densities $\left(\mathrm{TCR}^{\text {low }}\right)$. Thymocytes that do not undergo a productive TCR gene rearrangement die by apoptosis, whereas those expressing productive TCRs interact with peptides presented by molecules of the major histocompatibility complex (MHC), expressed on microenvironmental cells. This interaction determines the positive and negative selection events that are crucial for normal thymocyte differentiation. Positive selection allows the differentiation step through which immature, short-lived,

Editor: B. Brett Finlay, University of British Columbia, Canada

Citation: Savino W (2006) The thymus is a common target organ in infectious diseases. PLoS Pathog 2(6): e62. DOI: 10.1371/journal.ppat.0020062

DOI: $10.1371 /$ journal.ppat.0020062

Copyright: (c) 2006 Wilson Savino. This is an open-access article distributed under the terms of the Creative Commons Attribution License, which permits unrestricted use, distribution, and reproduction in any medium, provided the original author and source are credited.

Abbreviations: ECM, extracellular matrix; HAART, highly active antiretroviral therapy; IL, interleukin; MHC, major histocompatibility complex; RTE, recent thymic emigrant; SIV, simian immunodeficiency virus; TCR, T cell receptor; TEC, thymic epithelial cell; TNC, thymic nurse cell; TNF, tumor necrosis factor; TREC, T cell excision circle

Wilson Savino is at the Laboratory on Thymus Research, Department of Immunology, Oswaldo Cruz Institute, Inserm-Fiocruz Associated Laboratory of Immunology, Oswaldo Cruz Foundation, Rio de Janeiro, RJ, Brazil. E-mail: savino@ fiocruz.br 
$\mathrm{CD} 4^{+} \mathrm{CD} 8^{+}$thymocytes escape from programmed cell death and become mature, long-lived, $\mathrm{CD} 4^{+}$or $\mathrm{CD} 8^{+}$single-positive cells. This is a highly stringent process, sparing only a small proportion of the $\mathrm{CD} 4^{+} \mathrm{CD} 8^{+}$population. Positive selection also coincides with lineage commitment: the decision to become a $\mathrm{CD} 4^{+}$or $\mathrm{CD} 8^{+}$single-positive thymocyte, as a function of the class of MHC molecule with which the TCR can interact. Intrathymic negative selection is the screen that allows the establishment self-tolerance in the $\mathrm{T}$ cell repertoire, promoting apoptosis-mediated deletion of most $\mathrm{T}$ cells that might potentially react to self proteins.

Positively selected thymocytes that progress to the mature $\mathrm{TCR}^{\text {high }} \mathrm{CD} 4^{+} \mathrm{CD} 8^{-}$or $\mathrm{TCR}^{\text {high }} \mathrm{CD} 4^{-} \mathrm{CD} 8^{+}$single-positive stage constitute $15 \%$ of thymocytes that ultimately leave the organ to form the large majority of the peripheral $\mathrm{T}$ cell repertoire [1-4]. Figure 1 is a simplified view of the sequential steps of thymocyte differentiation within the context of the nonlymphoid compartment, the thymic microenvironment.

It is noteworthy that a small minority of potentially selfreactive thymocytes achieves the CD4 or CD8 single-positive stage and are released from the organ. Accordingly, along with differentiation into $\mathrm{CD} 4^{+}$single positive cells, some elements do not acquire the functional feature of typical helper cells (that is, cells able to trigger and/or enhance an immune response in the periphery), but rather differentiate into "regulatory" cells (most of them bearing the phenotype $\mathrm{CD} 4^{+} \mathrm{CD} 25^{+} \mathrm{FoxP}^{+}$), which actually block a given immune response. Recent data show that defects in such regulatory $\mathrm{CD} 4^{+} \mathrm{T}$ cells may be related to the occurrence of autoimmune events (reviewed in [5-7]).

Thymocyte differentiation occurs as cells migrate within the thymic lobules: $\mathrm{TCR}^{-} \mathrm{CD} 4^{-} \mathrm{CD} 8^{-}$and $\mathrm{TCR}^{+} \mathrm{CD} 4^{+} \mathrm{CD} 8^{+}$are cortically located, whereas mature $\mathrm{TCR}^{+} \mathrm{CD} 4^{+} \mathrm{CD} 8^{-}$and $\mathrm{TCR}^{+} \mathrm{CD} 4^{-} \mathrm{CD}^{+}$cells are found in the medulla (Figure 2). As this journey proceeds, thymocytes interact with various components of the thymic microenvironment, a threedimensional network formed of thymic epithelial cells (TECs), macrophages, dendritic cells, fibroblasts and extracellular matrix (ECM) components (Figure 2A).

In addition to the key interaction involving the TCR/ peptide-MHC, in the context of CD8 or CD4 molecules the thymic microenvironment influences thymocyte maturation via adhesion molecules and ECM; these interactions are relevant for thymocyte migration $[8,9]$. Moreover, microenvironmental cells modulate thymocyte differentiation by soluble polypeptides, comprising (a) typical cytokines, such as interleukin (IL)-1, IL-3, IL-6, IL-7, IL-8 and stem cell factor; (b) chemokines, including CXCL12, which preferentially attracts immature $\mathrm{CD} 4^{-} \mathrm{CD} 8^{-}$and $\mathrm{CD} 4^{+} \mathrm{CD} 8^{+}$ thymocytes, and CCL21, that exerts chemoattraction for mature single positive thymocytes [10-12]; and (c) thymic hormones such as thymulin, thymopoietin, and thymosin- $\alpha 1$, that can also act on the general process of thymocyte maturation $[3,13]$. Interestingly, not only the thymic epithelium affects thymocyte behavior, but thymocytes modulate some thymic epithelial functions, as exemplified by the role of interferon- $\gamma$ in the expression of MHC molecules, extracellular ligands, and receptors $[14,15]$. The various TEC/ thymocyte interactions are summarized in Figure 2B, and Table 1 summarizes accession numbers of peptide and DNA sequence databases of selected human and mouse proteins cited throughout this manuscript.

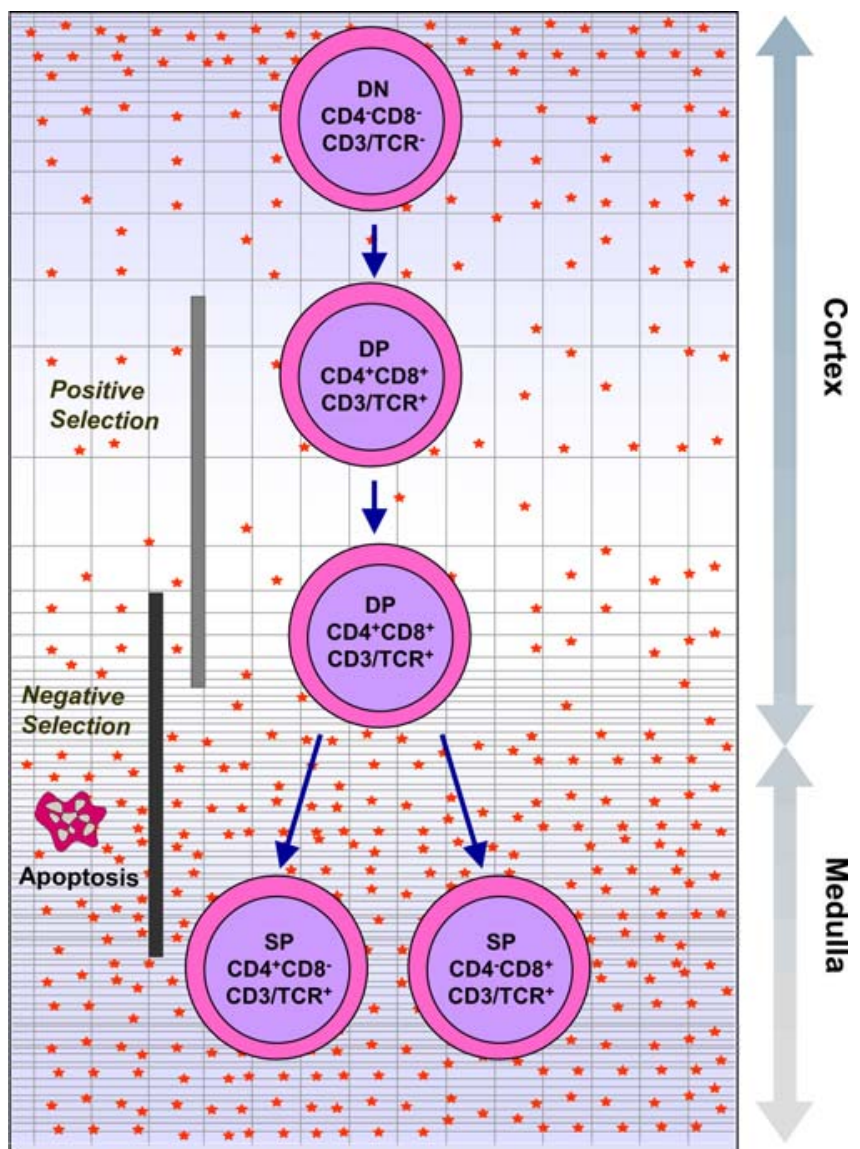

DOI: 10.1371/journal.ppat.0020062.g001

Figure 1. The Normal Process of Intrathymic T Cell Differentiation This diagram shows that most immature thymocytes localized in the subcapsular cortical region of the thymic lobules do not express CD4 or CD8 accessory molecules, nor the CD3/TCR complex, and are known as double-negative (DN, for CD4 and CD8) cells. As they progress in differentiation, they begin to express on their cell membranes the TCR/ CD3 complex as well as CD4 and CD8, becoming double-positive (DP) thymocytes, which occupy most of the cortical region. These cells are then submitted to the processes of positive and negative selection, as a consequence of the interaction with the thymic microenvironment (gray network) through MHC-TCR interactions. Those cells undergoing negative selective die by apoptosis, whereas the small percentages of positively selected thymocytes progress in their differentiation, moving toward the medulla and becoming single-positive cells (SP) for either CD4 or CD8, both expressing high densities of CD3/TCR complex. These mature thymocytes can be exported from the thymus into the peripheral lymphoid organs. Finally, this overall process of thymocyte differentiation occurs in the context of the three-dimensional thymic microenvironment (gray network) through membrane interactions as well as soluble products (represented by red stars) released by microenvironmental cells. Modified from [9].

The thymic epithelial network is the major component of the thymic microenvironment, and it is responsible for positive selection of thymocytes. It is a morphologically and phenotypically heterogeneous tissue, and cells in different locations within the thymic lobules may be related to specific steps in T cell maturation [2]. One cortically located lymphoepithelial complex, the thymic nurse cell (TNC), has been isolated in vitro. TNCs are lymphoepithelial multicellular structures formed by one TEC (which in mice can harbor 20-200 thymocytes), and are located in the cortical region of thymic lobules. Most intra-TNC lymphocytes bear the $\mathrm{CD} 4^{+} \mathrm{CD} 8^{+}$double-positive phenotype, 

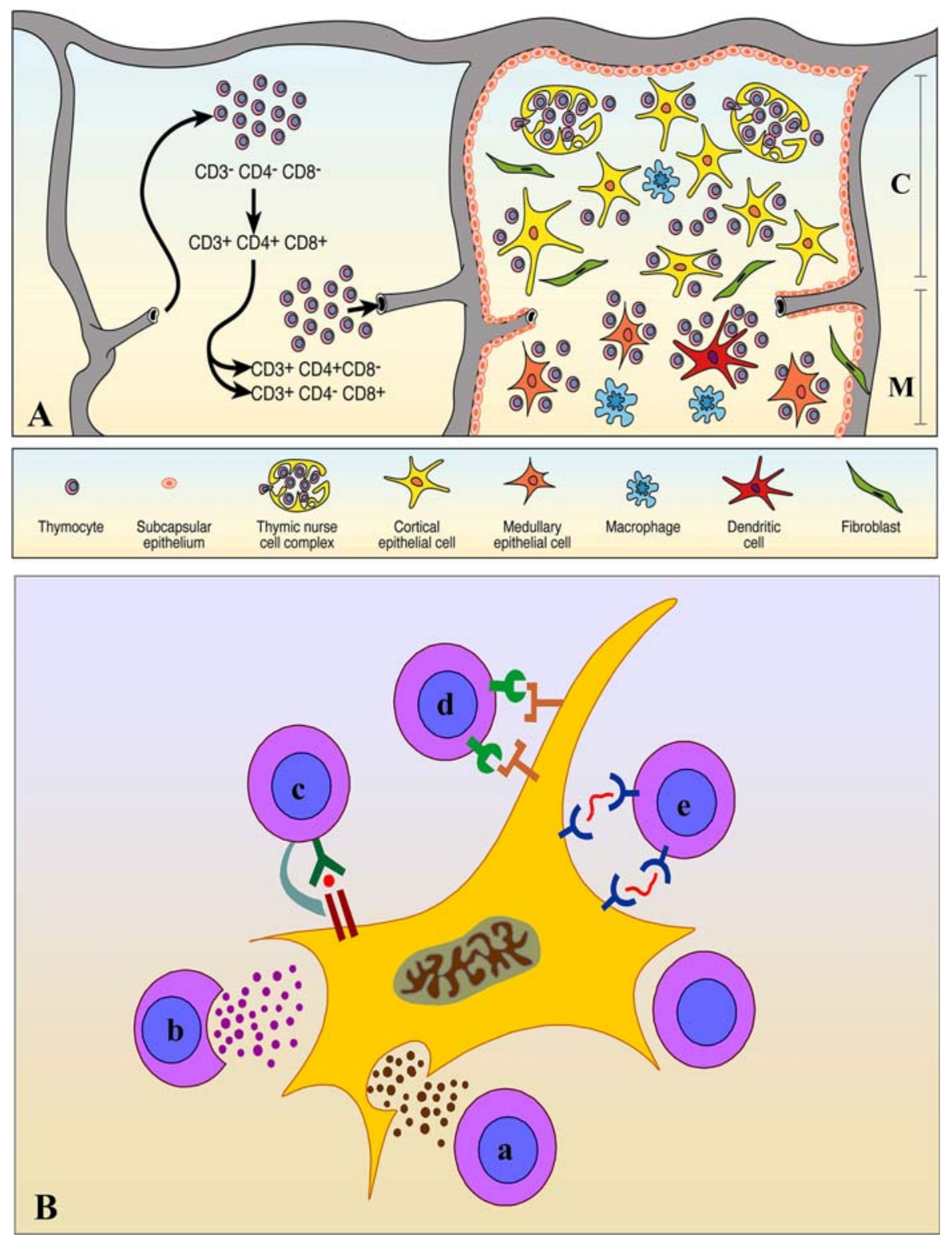

DOI: 10.1371/journal.ppat.0020062.g002

Figure 2. The Thymic Microenvironment and Its Role in Thymopoiesis

(A) A simplified model of thymocyte migration includes two compartments. On the left is depicted the entrance site of precursor cells into the thymus through blood vessels. Having entered the thymus, thymocytes migrate during differentiation to ultimately leave the organ, bearing the mature phenotypes of $\mathrm{CD}^{+} \mathrm{CD}^{-}$or $\mathrm{CD}^{-} \mathrm{CD}^{+}$cells. The right side of the image is a schematic representation of a thymic lobule, showing thymocytes intermingled with a heterogeneous cellular network, the thymic microenvironment, composed of epithelial cells (yellow and orange), dendritic cells (red), macrophages (blue), and fibroblasts (green). The epithelial tissue shows morphologic heterogeneity that can be seen in subseptal/subcapsular, cortical, and medullary regions. In the cortex, we note a particular lymphoepithelial complex, the TNC.

(B) A number of molecular interactions take place between developing thymocytes and thymic epithelial cells. Whereas a and $\mathrm{b}$ correspond to interactions mediated by soluble secretory molecules produced by epithelial cells (a) or lymphocytes (b), the interaction shown in c involves a given peptide (red dot) being presented by MHC (expressed by the epithelial cell) to the TCR and corresponding accessory molecule in the thymocyte membrane. The interaction shown by (d) involves adhesion molecules and the respective membrane counter-receptors, and (e) depicts an interaction mediated by ECM ligand and receptor. Modified from [3,8].

although immature double-negative as well as mature singlepositive cells can be found. TNCs may create special microenvironmental conditions for thymocyte differentiation and/or proliferation, and within this complex distinct interactions occur, comprising those mediated by soluble products, ECM, and MHC/TCR [3]. Once settled in culture, TNCs spontaneously release thymocytes, and TNCderived epithelial cells can reconstitute lymphoepithelial complexes after being cocultured with immature thymocytes [16]. Thus, TNCs constitute an in vitro model of thymocyte migration within the TEC context.

The thymocyte differentiation process and the thymic microenvironment compartment can be regarded as potential targets for direct or indirect effects of a given infectious agent. 
Table 1. Protein and Gene Accession Numbers of Selected Proteins

\begin{tabular}{|c|c|c|c|c|c|}
\hline \multirow[t]{2}{*}{ Protein Type } & \multirow[t]{2}{*}{ Protein } & \multicolumn{2}{|c|}{ Peptide Sequences $^{a}$} & \multicolumn{2}{|c|}{ DNA Sequences $^{a}$} \\
\hline & & Human & Mouse & Human & Mouse \\
\hline \multirow[t]{5}{*}{ Cytokines/chemokines } & IL-2 & P60568 & P04351 & 3558 & 16183 \\
\hline & IL-7 & P13232 & P10168 & 3574 & 16196 \\
\hline & IFN- $\gamma$ & P01579 & P01580 & 3458 & 15978 \\
\hline & TNF- $\alpha$ & P0137 5 & P06804 & 7124 & 21926 \\
\hline & CXCL-12 & P48061 & P40224 & 6387 & 20315 \\
\hline \multirow[t]{4}{*}{ ECM } & Laminin ( $\alpha 1$-chain) & P25391 & P19137 & 284217 & 16772 \\
\hline & Fibronectin (plasma) & $\mathrm{P} 02751$ & P11276 & 2335 - FN1 & 14268 \\
\hline & Galectin-1 & P09382 & P16045 & 3956 & 16852 \\
\hline & Galectin-3 & P17931 & P16110 & 3958 & 16854 \\
\hline \multirow[t]{8}{*}{ Membrane receptors } & CD3 & $\mathrm{P} 07766 \mathrm{CD} 3 \varepsilon$ & $\mathrm{P} 22646 \mathrm{CD} 3 \varepsilon$ & $916 \varepsilon$ chain & $12501 \varepsilon$ chain \\
\hline & CD4 & P01730 & P06332 & 920 & 12504 \\
\hline & CD8 & P01732 CD8 $\alpha$ & P01731 CD8 $\alpha$ & $925 \mathrm{CD} 8 \alpha$ & 12525 CD8 $\alpha$ \\
\hline & TNF-R1 & Q13077 & P25118 & 33638 & 21937 \\
\hline & CD49d & P13612 & Q00651 & 3676 & 16401 \\
\hline & CD49e & P08648 & P11688 & 3678 & 16402 \\
\hline & CD49f & P23229 & Q61739 & 3655 & 16403 \\
\hline & CXCR4 & P61073 & P70658 & 7852 & 12767 \\
\hline
\end{tabular}

${ }^{a}$ Accession numbers were retrieved from the SwissProt and LocusLink databases for peptide and nucleotide sequences, respectively.

CD49d, $\alpha 4$ integrin-chain of the fibronectin receptor VLA-4; CD49e, $\alpha 5$ integrin-chain of the fibronectin receptor VLA-5; CD49f, $\alpha 6$ integrin-chain of the laminin receptor VLA-6; IFN- $\gamma$, interferon- $\gamma$; TNF-R1, type-1 TNF receptor.

DOI: 10.1371/journal.ppat.0020062.t001

Thymic atrophy is a common feature in infectious diseases.

A common feature seen in a variety of acute infections is severe atrophy of the thymus, largely reflecting intense lymphocyte depletion, particularly of cortical thymocytes bearing the phenotype $\mathrm{CD} 4^{+} \mathrm{CD} 8^{+}$(Figure 3 and Table 2). This depletion actually corresponds to massive cortical thymocyte apoptosis, as it has been shown in a variety of infections, including viral diseases such as AIDS, simian immunodeficiency syndrome, and rabies; experimental bacterial infections such as turalemia and listeriosis; diseases caused by parasites including T. cruzi, Plasmodium chaubi, Schistosoma mansoni, and Trichinella spiralis; and fungal infections, exemplified by experimental infections with Paracoccidioides brasiliensis and Histoplasma capsulatum [17-36]. In some cases, thymocyte loss is so great that the cortical region of thymic lobules virtually disappears as a consequence of the severe $\mathrm{CD} 4^{+} \mathrm{CD} 8^{+}$thymocyte depletion.

The precise mechanisms responsible for the thymic atrophy seen in acute infections are not completely elucidated, and may vary in distinct diseases. One major pathway is related to the rise in glucocorticoid hormone levels in the blood, a classical effect comprised within the organism's stress response to the infection. It is well known that such steroids can trigger apoptosis in thymocytes, acting via a specific receptor, a ligand-activated transcription factor [37]. $\mathrm{CD}^{+} \mathrm{CD}^{+}$thymocytes are particularly sensitive to glucocorticoids, with the activation of caspase- $3,-8$, and -9 [38], whereas mature single-positive thymocytes are much more resistant, through a mechanism dependent on CD28 signaling [39].

Thymocyte depletion in rabies virus-infected mice [40] can be prevented by adrenalectomy prior to infection, clearly indicating that in this case, cell death is related to increased serum glucocorticoid [41]. Ablation of the adrenal glands also prevents the thymocyte depletion seen in the experimental infection by the bacterium Francisella tularensis [24].

Nevertheless, in this case, tumor necrosis factor (TNF)- $\alpha$ also seems to be involved, since thymic atrophy was not seen in TNR receptor-deficient mice infected with $F$. tularensis [25]. Nevertheless, in the murine model of experimental Chagas disease, despite the high levels of corticosterone seen in acutely and chronically infected animals [28,42], adrenalectomy did not prevent T. cruzi-induced cortical thymocyte depletion.

The relative role of glucocorticoids upon intrathymic cell death seen in several acute infections deserves to be revisited. As we summarized above, currently available data are based on the rise of serum glucocorticoid hormone levels, as well as on adrenalectomy experiments. These indicators do not take into account the intrathymic production of functional glucocorticoids by thymic epithelial cells (reviewed in $[37,43,44])$. Accordingly, it is completely unknown whether the intrathymic levels of glucocorticoids vary in infected individuals, and if so, what the local consequences are in terms of the general process of thymocyte differentiation.

As already exemplified by experimental tularemia, other death-related molecular pathways (such as the one triggered by TNF) may be involved in the generation of thymic atrophy seen in infectious diseases. Unfortunately, as regards experimental T. cruzi infection, the putative role of TNF- $\alpha$ in thymocyte depletion has not been investigated so far. This topic should be studied, in view of the data showing the enhanced intrathymic contents of this death-related cytokine [45], and our recent findings that TNF- $\alpha$ is actually involved in the $\mathrm{CD} 8^{+} \mathrm{T}$ cell apoptosis seen in mesenteric lymph nodes from T. cruzi-infected mice [46].

Studies performed in Fas-deficient gld/gld as well as in perforin knockout mice revealed a significant thymic atrophy upon T. cruzi infection, thus discarding the involvement of interactions mediated by Fas/Fas-L or perforin in triggering 


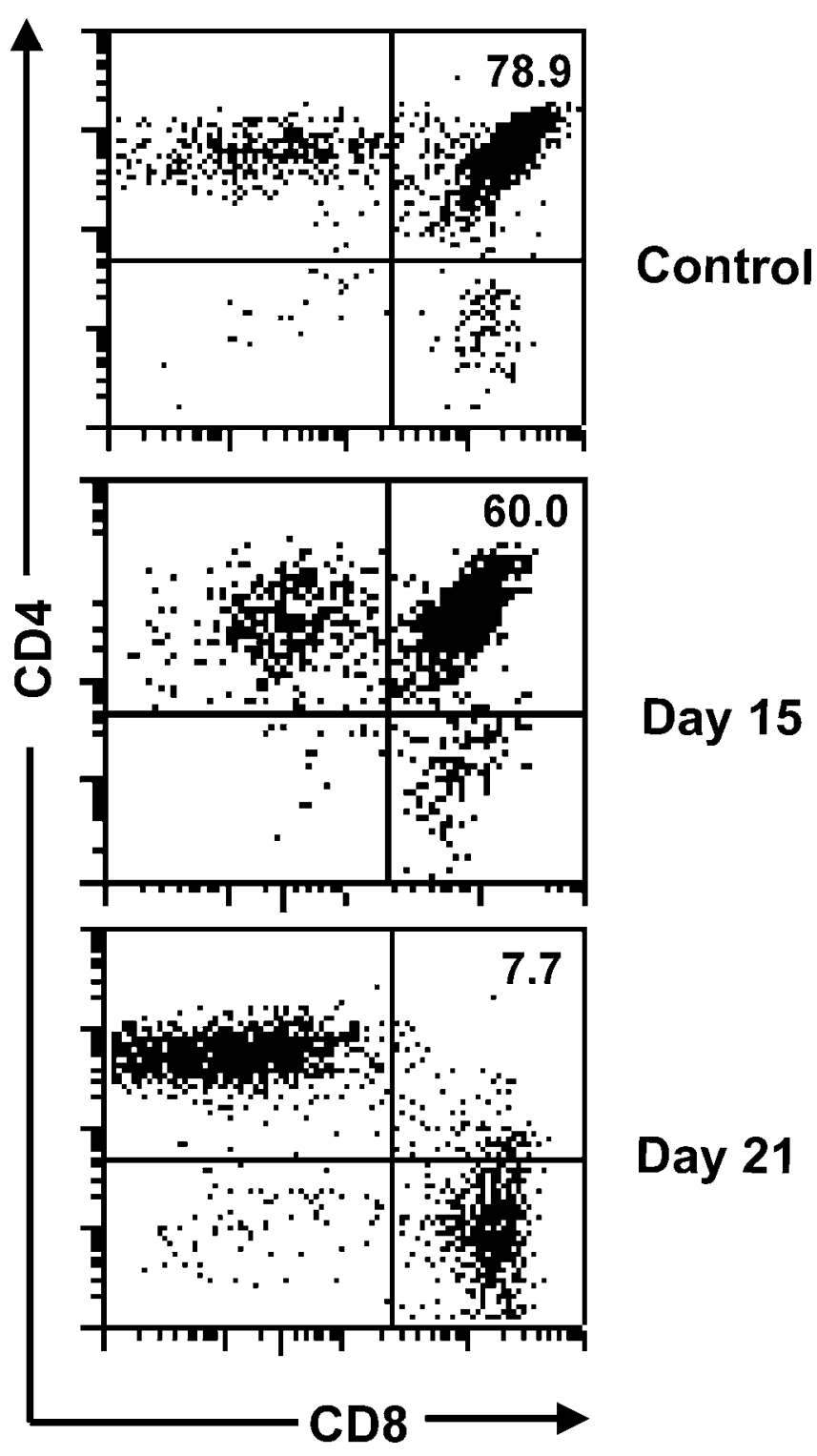

DOI: 10.1371/journal.ppat.0020062.g003

Figure 3. Progressive Thymic Atrophy in Mice Acutely Infected by T. cruzi A typical CD4/CD8-defined cytofluorometric profile of normal thymocytes compared to that with $T$. cruzi infection. As infection progresses, we can see a progressive loss of $\mathrm{CD} 4^{+} \mathrm{CD} 8^{+}$cells. Percentage values of the $\mathrm{CD} 4^{+} \mathrm{CD} 8^{+}$subset are shown within the quadrants. The days correspond to the time of infection, with an inoculum of $10^{5}$ parasites per animal. The peak of parasitemia coincides with the peak of thymocyte depletion. Modified from [43].

cell death within the thymus [47]. By contrast, two distinct mechanisms have been implicated in the thymic atrophy occurring in experimental Chagas disease. A nonvirulent strain of the parasite did not induce thymic atrophy or thymocyte depletion [48], suggesting that parasite-derived factors could be involved. This result is in keeping with the data showing that the specific treatment of the disease with benznidazole prevents intrathymic $\mathrm{CD} 4^{+} \mathrm{CD} 8^{+}$cell depletion [49]. Accordingly, Mucci and coworkers [50] observed that apoptosis seen in thymic nurse cell complexes from infected mice could be due to the parasite-derived enzyme trans- sialidase. In a second study, it was showed that thymocytes from infected mice were particularly sensitive to the proapoptotic action of extracellular ATP, acting through the $\mathrm{P}_{2} \mathrm{X}_{7}$ purinergic receptor [51]. Moreover, we recently noticed that thymocyte depletion associated with T. cruzi infection was not seen in galectin-3 knockout mice (unpublished data), thus suggesting a role for this molecule in the infectioninduced thymocyte loss, in addition to its de-adhesion role [52]. Conjointly, these data indicate that depletion of thymic lymphocytes may result from multiple interactions involving both endogenous and infectious agent-derived moieties. As further discussed below, it is noteworthy that several infectious agents can reach the thymic parenchyma, as it has been shown for some viruses, protozoa, and fungi $[27,32,34,53]$

Very few studies have been done to address the question of the fate of dead thymocytes seen in infectious diseases.

Nevertheless, most likely they are phagocytosed by intrathymic macrophages, as it has been demonstrated following infection of macaques with simian immunodeficiency virus (SIV) [18].

Lastly, it is worthwhile to mention that coinfection may have an impact on thymocyte apoptosis. Although literature on this issue is very scarce, it has been shown that coinfection of mice with hepatitis virus type 3 and T. cruzi yielded a higher degree of apoptosis (ascertained by in situ TUNEL labeling) than that of each infection alone [48]. Considering the growing medical importance of coinfection in AIDS, this point certainly deserves further investigation.

Intrathymic cell proliferation and cytokine production in infectious diseases. In addition to intrathymic apoptosis, which takes place in a variety of experimental and human infectious diseases, mitogenic responses of thymocytes can be altered. We found a significant decrease in both concanavalin A- and anti-CD3-driven proliferative responses in thymocytes from T. cruzi-infected mice compared to controls. This decrease was paralleled by a decrease in IL-2 production [54]. At the same time, we observed an increase in IL-10 as well as IFN- $\gamma$ secretion by thymocytes from infected animals that originated from the decreased IL-2 and consequent diminished proliferative response: the in vitro treatment of cultured thymocytes from T. cruzi-infected animals with blocking antibodies to IL-10 and IFN- $\gamma$ did restore IL-2 production and thymocyte proliferation induced by mitogens [54]. In a second vein, the ex vivo increase in the production of IL-4, IL-5, and IL-6 could be at least partially involved in the appearance of cytotoxic activity seen in thymuses from infected mice [54].

Experiments performed in SCID-hu mice (mouse chimeras bearing human $\mathrm{T}$ cells derived from transplantation of human thymic fragments and liver tissue under the renal capsule) revealed an increase of IL- 6 and IFN- $\gamma$ mRNA in thymocytes from HIV-infected mice, where IL-2 mRNA was decreased as ascertained by conventional RT-PCR [55]. This study also showed that antiretroviral therapy tended to increase the levels of cytokine mRNAs and to restore the proportions of the various CD4/CD8-defined thymocyte subpopulations.

The thymic microenvironment in infectious diseases. In addition to the changes seen in thymic lymphocytes in various infectious diseases, the microenvironmental compartment of the organ can be affected. In experimental $T$. 
Table 2. Thymic Atrophy in Human and Experimental Infectious Diseases

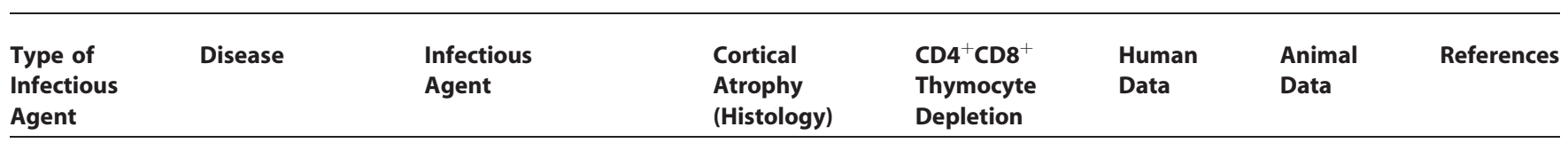

\begin{tabular}{|c|c|c|c|c|c|c|c|}
\hline \multirow[t]{5}{*}{ Viruses } & AIDS & HIV/SIV & + & + & + & + & {$[17,18,70,72]$} \\
\hline & Rabies & Rabies virus & + & + & ND & + & {$[20,40,85]$} \\
\hline & Measles & Measles virus & + & + & + & + & [86-88] \\
\hline & Hepatitis & Hepatitis virus (A59) & ND & + & ND & + & {$[22]$} \\
\hline & Ebola infection & Ebola virus & + & ND & ND & + & {$[21]$} \\
\hline \multirow[t]{3}{*}{ Bacteria } & Tularemia & F. tularensis & + & + & ND & + & {$[24,25]$} \\
\hline & Listeriosis & Listeria monocytogenes & + & + & ND & + & {$[26]$} \\
\hline & Syphilis & Treponema pallidum & + & ND & + & & [32] \\
\hline \multirow[t]{2}{*}{ Protozoa } & Chagas disease & T. cruzi & + & + & + & + & {$[27-29,47,50]$} \\
\hline & Malaria & P. chabaudi & + & ND & ND & + & [30] \\
\hline \multirow[t]{3}{*}{ Fungi } & Paracocciodosis & P. brasiliensis & + & ND & ND & + & {$[34,35]$} \\
\hline & Histoplasmosis & H. capsulatum & + & + & ND & + & [36] \\
\hline & Neosporosis & Neospora caninum & + & ND & ND & + & [89] \\
\hline \multirow[t]{2}{*}{ Helminths } & Schistosomiasis & S. mansoni & + & ND & ND & + & {$[31,32,90]$} \\
\hline & Trichinosis & Trichinella spiralis & + & ND & ND & + & [33] \\
\hline
\end{tabular}

ND, not determined.

DOI: 10.1371/journal.ppat.0020062.t002

cruzi infection, for example, we noticed changes in TEC phenotypes: some cortical TECs expressed cytoskeletal markers normally restricted to the medullary epithelium. Simultaneously, epithelial cells in the medulla expressed the cytokeratin pair $8 / 18$, which is restricted to cortical TECs in normal conditions [27]. It is noteworthy that such changes are not specific of the infection by T. cruzi, since they were also found in mice infected with Schistosoma mansoni [32].

In some viral infections, such as those caused by HIV and measles virus, the thymic epithelium is also severely damaged, with changes in phenotype and induction of apoptosis in adjacent thymocytes $[17,56]$. Studies performed with in vitro infection of human TECs by measles virus revealed that, in addition to inducing apoptosis in thymocytes, the virus arrests cell growth and induces terminal differentiation of the thymic epithelium [56].

In keeping with the densification of the TEC network, seen in vivo following some acute infections, including experimental Chagas disease, the MHC class II meshwork seen in the thymic microenvironment is also denser than the profiles seen in control thymuses [27]. Although solid data are scarce, this pattern is likely a general one in acute infections that generate atrophy of the thymic lobules, and thus it should be placed in the context of interactions with adjacent lymphocytes. It is conceivable that a denser MHC network results in an altered presentation of endogenous peptides to developing thymocytes, yielding alterations in the genesis of the intrathymic $\mathrm{T}$ cell repertoire. This issue will be further discussed below.

With respect to soluble products, we observed in T. cruziinfected mice a transient decrease in the serum levels of the thymic hormone thymulin [27], known to be restrictedly produced by TECs [3]. In human HIV infection a consistent and long-term diminution of thymulin secretion has also been documented, in terms of both serum levels and intrathymic contents of the hormone $[17,57,58]$.

Concerning microenvironmentally derived cytokines, studies using experimental HIV infection in humanized immunodeficient SCID-hu mice (pretransplanted with human thymic fragments) revealed an increase in IL-6 mRNA in the microenvironmental compartment of the thymus, although the levels of CXCL12 mRNA were not significantly altered [55].

An interesting feature is that interaction of thymocytes with thymic epithelial cells seems to be required for HIV replication in humans [59], leading to the secretion of various cytokines by the thymic epithelium, including IL-7, a major soluble factor in intrathymic $\mathrm{T}$ cell differentiation. In fact, the same research group showed more recently that TECderived IL-7 is able to up-regulate the expression of the CXC12 receptor CXCR 4 by mature $\mathrm{CD} 4^{+}$single-positive thymocytes, which favors HIV replication in these cells [60].

Regarding TEC-derived chemokines, in a recent study we noticed in T. cruzi-acutely infected mice an increase in the intrathymic contents of CXCL12 concomitant with an increase in the membrane density of CXCR4 in the corresponding thymocytes [12,61]. Unfortunately, we have not measured IL-7 production by TECs of infected animals or cultures; this study should be instructive in better

understanding the mechanisms leading to enhancement of CXCR4 expression.

In addition to soluble moieties, the intrathymic production of ECM is altered in infectious diseases (Figure 4). By using immunohistochemistry, we found increased deposition of ECM components such as laminin, fibronectin, and type IV collagen in various human and experimental acute infectious diseases, including rabies, syphilis, measles, Chagas disease, and schistosomiasis [32]. One could argue that such an increased in the intrathymic contents of ECM molecules merely reflects the atrophy of the organ, with a densification of the ECM-containing network as a result of thymocyte loss. Although such mechanical response is likely to occur, at least in experimental Chagas disease it does not solely account for the ECM increase, since in vitro T. cruzi infection of cultured thymic epithelial cells, as well as TEC cultures derived from in vivo-infected animals, does result in a enhancement of ECM 

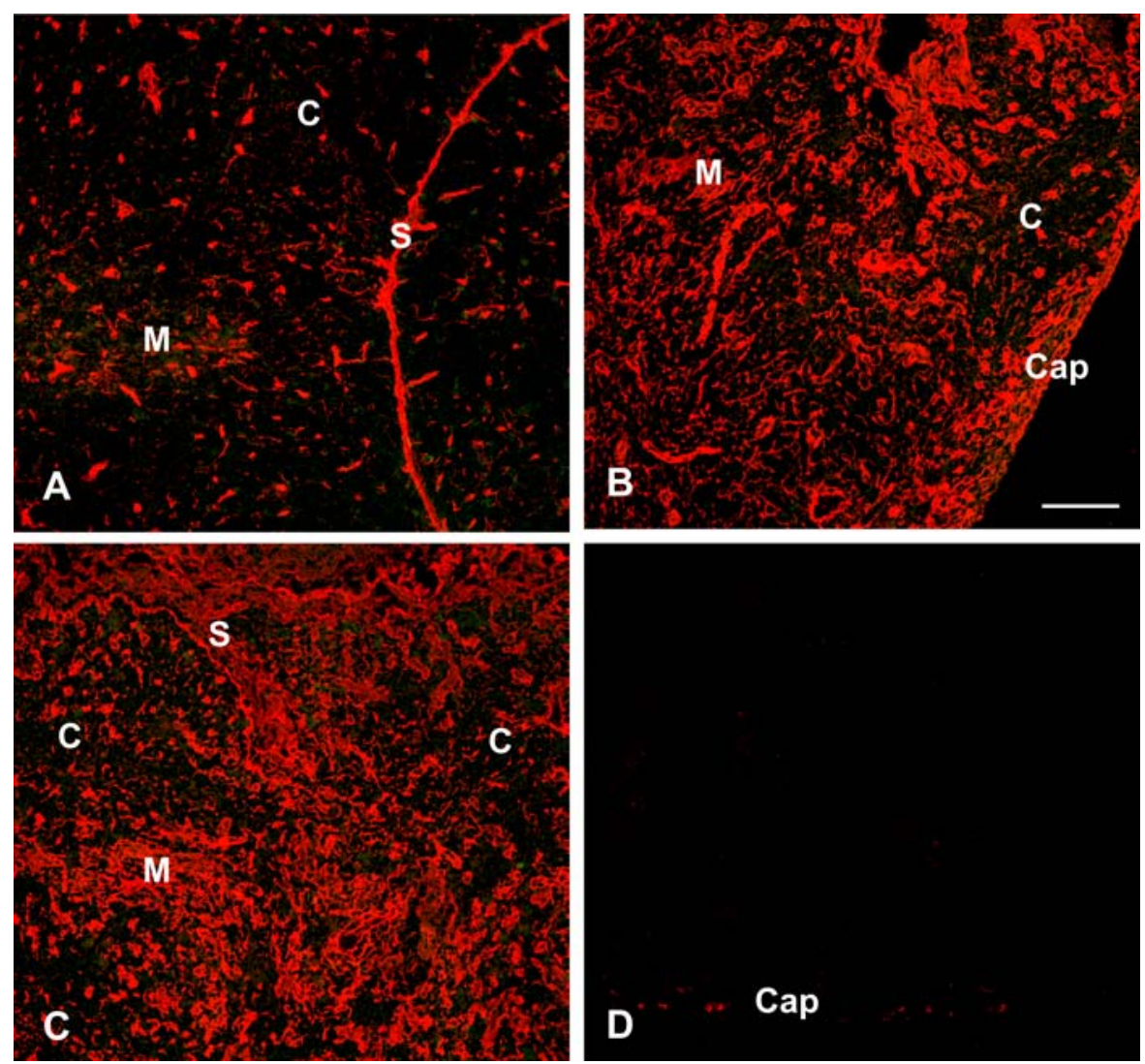

DOI: 10.1371/journal.ppat.0020062.g004

Figure 4. Increase in Intrathymic ECM Following Acute T. cruzi Infection in Mice

Cryostat sections of thymuses from normal (A) or T. cruzi-infected mice (B, C, and D) were immunostained with anti-fibronectin immune serum (A, B, and C) or unrelated antibody (D). In control thymus (A), the typical fibronectin-containing network is seen, being more prominent in the medullary region of the thymic lobule (M), as compared to the cortex (C). This pattern is dramatically changed in the atrophic thymuses from T. cruzi-infected animals (B and C), in which the fibronectin network is much denser in both cortex and medulla. Such immunolabeling is specific, since an unrelated antibody did not yield any significant fluorescence when applied on the thymus section from an infected mouse (D). Mice were infected with $10^{5}$ trypomastigote forms of the parasite (Colombian strain), and sacrificed $21 \mathrm{~d}$ later, at the peak of parasitemia. C, cortex; Cap, capsule; M, medulla; S, septum. Bar represents 100 $\mu \mathrm{m}$ for all photomicrographs. Pictures were kindly provided by Désio Aurélio Farias-de-Oliveira.

production [62]. Moreover, it is interesting to note that in thymuses from $T$. cruzi acutely infected mice, thymocytes exhibit an increase in membrane density of ECM receptors for fibronectin and laminin [63]. As detailed below, such features are likely related to alterations in the migratory patterns of thymocytes.

Intrathymic T cell migration in infectious diseases: Putative relationship with release of potentially autoreactive cells.

Changes in the patterns of peripheral $\mathrm{T}$ cell migration have been reported in infectious diseases, and can been demonstrated in Chagas disease [64-66]. Such changes are obviously necessary in T cell-dependent immune responses mounted against the infectious agent, although they can generate autoimmune events. Although relatively few data are available on migratory disturbances of $\mathrm{T}$ lymphocytes within the thymus, we obtained evidence that thymocyte migration is altered in experimental T. cruzi infection. As mentioned above, TNC complexes can be considered an in vitro model of thymocyte migration in the thymic epithelium. In mice experimentally infected with T. cruzi, we found a decrease in the number and size of TNCs [50,62], although thymocyte release from the remaining lymphoepithelial complexes was faster than from corresponding controls, an event likely due to the enhancement of ECM production. Similar results were observed when TNC complexes from normal animals were infected in vitro [62].

Considering that most intra-TNC thymocytes are immature $\mathrm{CD} 4^{+} \mathrm{CD} 8^{+}$cells, one could raise the hypothesis that the migratory capacity of these cells is enhanced in murine Chagas disease. Accordingly, we found a significant increase in the relative and absolute numbers of $\mathrm{CD} 4^{+} \mathrm{CD} 8^{+}$cells in peripheral lymphoid organs of T. cruzi-infected mice in both acute and chronic phases of the disease. These lymphocytes are actually $\mathrm{T}$ cells since they express variable amounts of CD3 and TCR on their membranes [63,64]. Moreover, the thymic dependence of this increase in peripheral $\mathrm{CD} 4^{+} \mathrm{CD} 8^{+}$ $\mathrm{T}$ lymphocytes was demonstrated by the fact that it could be prevented in animals that were thymectomized prior to infection [63].

As seen in Figure 5, CD $4^{+} \mathrm{CD} 8^{+}$peripheral $\mathrm{T}$ cells seen in experimental Chagas disease exhibited higher amounts of ECM receptors including the integrins VLA-4, VLA-5, and VLA-6 [65-69], indicating that an abnormal ECM-mediated interaction could be favoring the release of immature thymocytes from the organ.

More recently, we found that multiple driving forces likely 


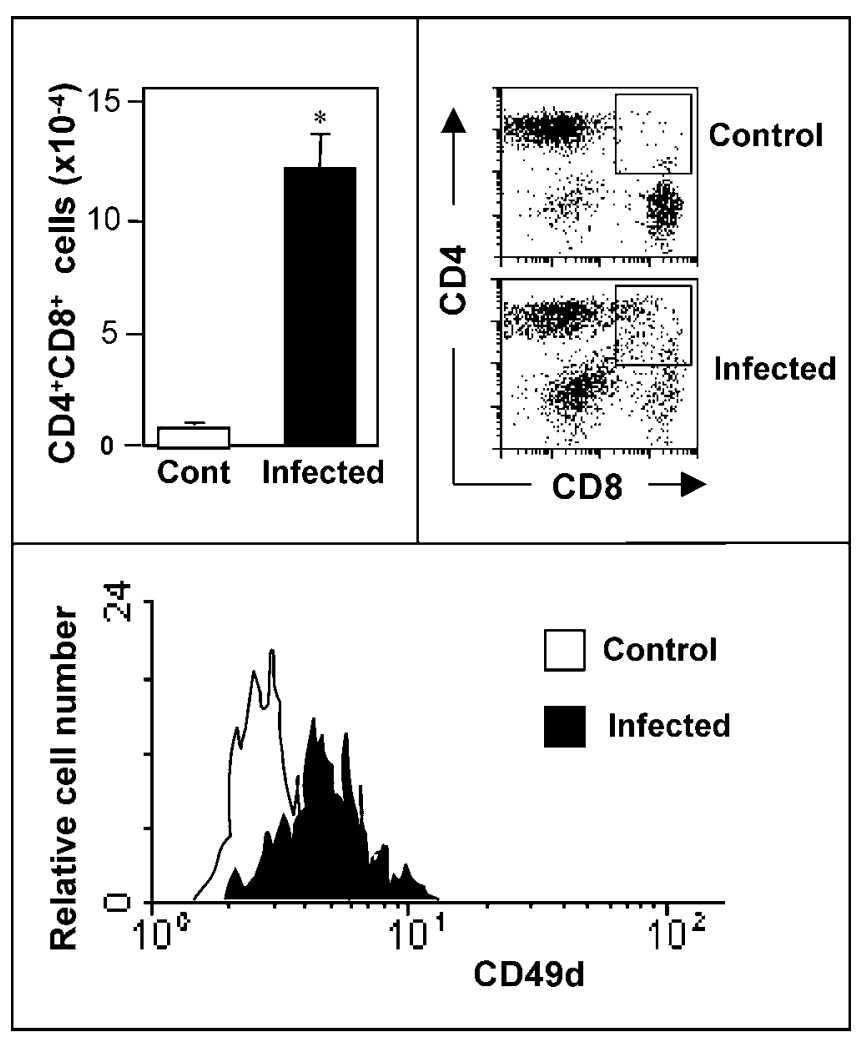

DOI: 10.1371/journal.ppat.0020062.g005

Figure 5. Appearance of Immature Thymus-Derived T Cells in Lymph Nodes of $T$. cruzi-Infected Mice

The bar graph at the upper left shows the significant increase in the absolute numbers of $\mathrm{CD}^{+} \mathrm{CD}^{+}$lymphocytes seen in subcutaneous lymph nodes of acutely infected mice. The flow cytometry dot plots to the right show the enhancement of these $\mathrm{CD} 4^{+} \mathrm{CD} 8^{+}$cells in the infected animal and compared to the age-matched control. These immature double-positive T cells express higher amounts of the fibronectin receptor VLA-4, as ascertained by the cytofluorometric detection of the CD49d integrin subunit (bottom graph). Adapted from [43].

favor export of $\mathrm{CD} 4^{+} \mathrm{CD} 8^{+}$cells from the thymus of infected animals. Following acute T. cruzi infection, intrathymic CXCL12 contents increase and thymocytes from infected animals express higher levels of the corresponding receptor CXCR4. Accordingly, CXCL12 has a synergic effect with fibronectin in enhancing ex vivo migratory response of these cells [61].

A second aspect deserving comment is that some of the $\mathrm{CD} 4^{+} \mathrm{CD} 8^{+}$cells seen in the periphery of infected animals appears to have bypassed intrathymic events of negative selection. In experiments performed on lymph nodes of acutely or chronically infected BALB/c mice, we found immature $\mathrm{CD} 4^{+} \mathrm{CD} 8^{+}$cells as well as mature $\mathrm{T}$ cells bearing "forbidden" TCRs that should have been deleted in thymus, including those belonging to the V $\beta 5$ and V $\beta 12$ TCR $\beta$ families [64]. Conjointly, these data indicate that such $\mathrm{CD} 4^{+} \mathrm{CD} 8^{+}$cells abnormally released from the thymus of $T$. cruzi infected have bypassed intrathymic negative selection, thus bearing a potential autoreactive phenotype that apparently differentiates in the periphery into $\mathrm{CD} 4^{+}$or $\mathrm{CD} 8^{+}$ single-positive cells [64]. In this respect, it is noteworthy that $\mathrm{CD}^{+} \mathrm{T}$ cell-mediated autoreactivity against myocardial cells has been experimentally demonstrated in murine Chagas disease [68,69].

The findings discussed above illustrate the notion that the ability of the thymus to release lymphocytes into the periphery of the immune system is crucial for determining the role of this organ in the pathophysiology of infectious disease. This ability can be evaluated through the analysis of the so-called "recent thymic emigrants" (RTEs) [11]. In experimental animals, these cells can be tracked in the periphery, following intrathymic labeling of lymphocytes with fluorescein isothiocyanate. The FITC $^{+}$cells seen in peripheral lymphoid organs or in the blood are those recently exported from the thymus. Alternatively, RTEs can be evaluated by the presence of $\mathrm{T}$ cell excision circles (TRECs), circular DNA fragments derived from the rearrangement of TCR genes that remain within mature thymocytes and RTEs. This is the method mostly used for determining RTEs in humans.

In the case of experimental Chagas disease, the idea is plausible that changes in thymocyte migration are at the origin of the release of potentially autoreactive $\mathrm{T}$ cell clones. Nevertheless, this notion remains as a hypothesis, since the actual autoimmune nature of these cells has not been established. In a broader sense, it will be worthwhile to search for potentially autoreactive cells in other infectious diseases, to better understand the role of the thymus in these conditions.

Despite the abnormal release of immature thymocytes seen in acute T. cruzi infection, the overall rate of mature thymocyte export in infectious disease is likely lower than what is seen in normal conditions, due to the low absolute numbers of these cells in the thymus. Because of the degree of thymic atrophy seen in these acutely infected animals, tracing RTEs in the periphery of the immune system by intrathymic injection of fluorescein isothiocyanate was not technically feasible (unpublished data), and the analysis of $\mathrm{TREC}^{+}$cells has not been done so far.

By contrast, TREC analysis has been performed in human and simian immunodeficiency virus infections, and in both cases the numbers of TREC ${ }^{+} \mathrm{T}$ lymphocytes in the peripheral blood were lower than in uninfected individuals [18,70]. Importantly, specific highly active antiretroviral therapy (HAART) in AIDS patients promoted an increase in recent thymic emigrants, or TREC ${ }^{+}$cells, in the blood [71]. Actually, this effect could be further enhanced by using HAART plus growth hormone treatment [72]. Patients considered poor responders to HAART exhibited minimal thymic tissue (as defined by computer tomography scanning) and had significantly fewer circulating $\mathrm{TREC}^{+} \mathrm{CD} 4^{+} \mathrm{T}$ cells than did the good HAART responders [73], indicating that poor $\mathrm{CD}^{+}$ $T$ cell replenishment in treated AIDS patients may in part reflect decreased thymic function. In addition, long-term survivors of pediatric HIV infection showed recovery of thymic volume and numbers of circulating TRECs to levels that reached values similar to uninfected age-matched individuals [74].

Modulation of thymocyte export in AIDS may be a direct effect of virus-derived proteins on $\mathrm{T}$ cells. It has been determined that the HIV nef regulatory protein alone is able to inhibit CXC12-induced migration of peripheral $\mathrm{CD} 4^{+} \mathrm{T}$ cells by interfering with the CXCR4 downstream signaling pathway [75]. 
A different scenario has been drawn for measles virusinfected children, in which an increased relative number of TREC $^{+}$cells were reported despite the existence of thymic atrophy [76]. Nevertheless, this conclusion should be made with caution, since in parallel with the slight (although statistically significant) relative increase of circulating RTEs, the authors also reported that the same children had severe lymphopenia that corresponded to a $50 \%$ decrease in total numbers of lymphocytes. Thus, in terms of absolute cell export from the thymus, a decrease (rather than an increase) in exit of thymocytes may occur following human measles virus infection.

Anti-thymus antibodies in infectious diseases. In addition to the mechanisms discussed above, in terms of the changes seen in both lymphoid and microenvironmental compartments of the thymus with infectious diseases (that in some cases may be related to an abnormal release of potentially autoreactive cells), there is evidence that the thymus itself is a target of autoimmune events. For example, we found anti-TEC and anti-thymocyte antibodies in both acute and chronic phases of experimental and human Chagas disease [27,77]. In human syphilis, we observed immunoglobulin deposits in basement membrane of thymic lobules and increased numbers of B cells within the thymic lobules (unpublished data). Intrathymic deposits of immunoglobulins and complement, as well as plasma cells, were also reported in AIDS patients [27,78]. Importantly, circulating self-reactive antibodies from AIDS patients promoted massive thymocyte destruction when injected into normal mice [79]. Thus, it is possible that intrathymic antibody deposition may play a role in thymic functions under the context of a given infectious disease. This hypothesis obviously needs to be better evaluated, but represents an interesting field of investigation.

Intrathymic detection of infectious agents. The various aspects discussed above, concerning both the lymphoid and microenvironmental changes of the thymus in infectious diseases, lead to an obvious question: To what extent are these alterations due to a direct intrathymic effect of the given infectious agent? To answer this question a first approach is to define whether or not the infectious agent (or respective-derived moieties) can be detected intrathymically. Rather surprisingly, despite the existence of the so-called blood-thymus barrier, infectious agents have been detected within the organ, including viruses (HIV, SIV, lymphocoriomeningitis, etc.), protozoan parasites such as $T$. cruzi, and even fungi, as exemplified by Paracoccidioides brasiliensis in Figure 6.

We found T. cruzi parasites in both thymic macrophages and epithelial cells [53]. Accordingly, these

microenvironmental components can be infected in vitro, as seen in Figure 7. In this case, intrathymic infection may play a direct role in generating thymic atrophy, since the parasitederived trans-sialidase is likely at the origin of thymocyte death seen in acutely infected animals [50].

Measles virus can also infect the thymic epithelium, both in vivo and in vitro. Studies using human TEC cultures showed that the virus can enter the cells via a specific membrane protein termed the nucleoprotein receptor [80].

Choriomeningitis virus, as well as HIV and SIV, are able to infect thymic lymphocytes. Moreover, it is likely that HIV infects the thymic microenvironment, since a significant viral

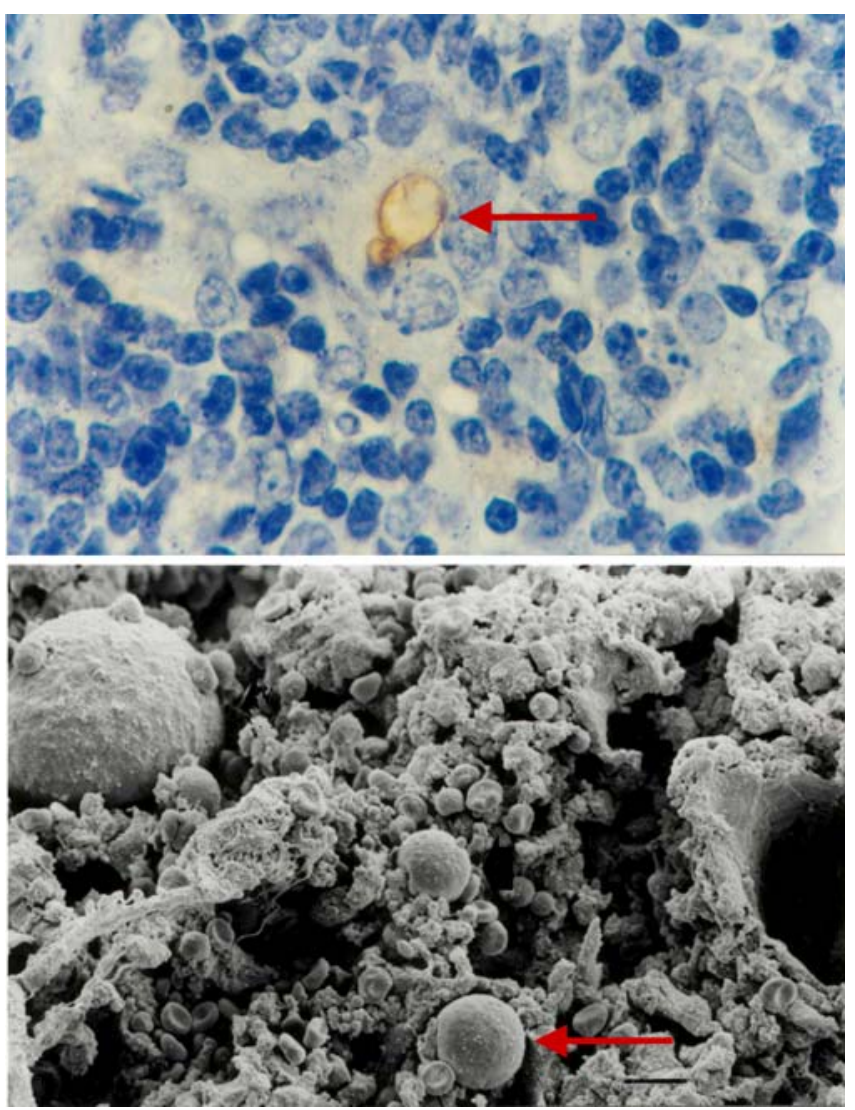

DOI: 10.1371/journal.ppat.0020062.g006

Figure 6. Intrathymic Presence of the Fungus $P$. brasiliensis Fungus particles (red arrows) are shown by immunohistochemistry (upper image) and scanning electron microscopy (lower image). Note that infective particles are encircled by microenvironmental cells bearing large nuclei. Pictures were kindly provided by Dr. Liana Verinaud.

load was found in the microenvironmental compartment of the thymus in HIV-infected SCID-hu mice [55], a finding that was recently confirmed by the demonstration of infected thymic dendritic cells [81]. Whether or not the thymic epithelium is also infected by this virus is an issue that deserves further investigation.

Conceptually, the fact that some infectious agents enter the thymus and infect thymic cells raises the hypothesis of central tolerance for at least some infectious agent-derived antigens. This issue remains largely unexplored and represents a relevant field for further investigation.

Conversely, intrathymic manipulation also offers a potential way to enhance the ability of $\mathrm{T}$ cells to control infection. This will be hopefully be achieved through the use of so-called "thymic vaccination." The concept is based on the fact that slightly altered peptides bearing lower affinity to the corresponding TCR than to the natural cognate ligand may induce positive selection of this molecule when injected intrathymically, leading to antigen-specific T cell export from the thymus $[82,83]$. Accordingly, in theory it should be possible to enhance the immune response against a given infection agent by increasing the numbers of positively selected thymocytes able to recognize a given molecule of the corresponding infectious agent. 

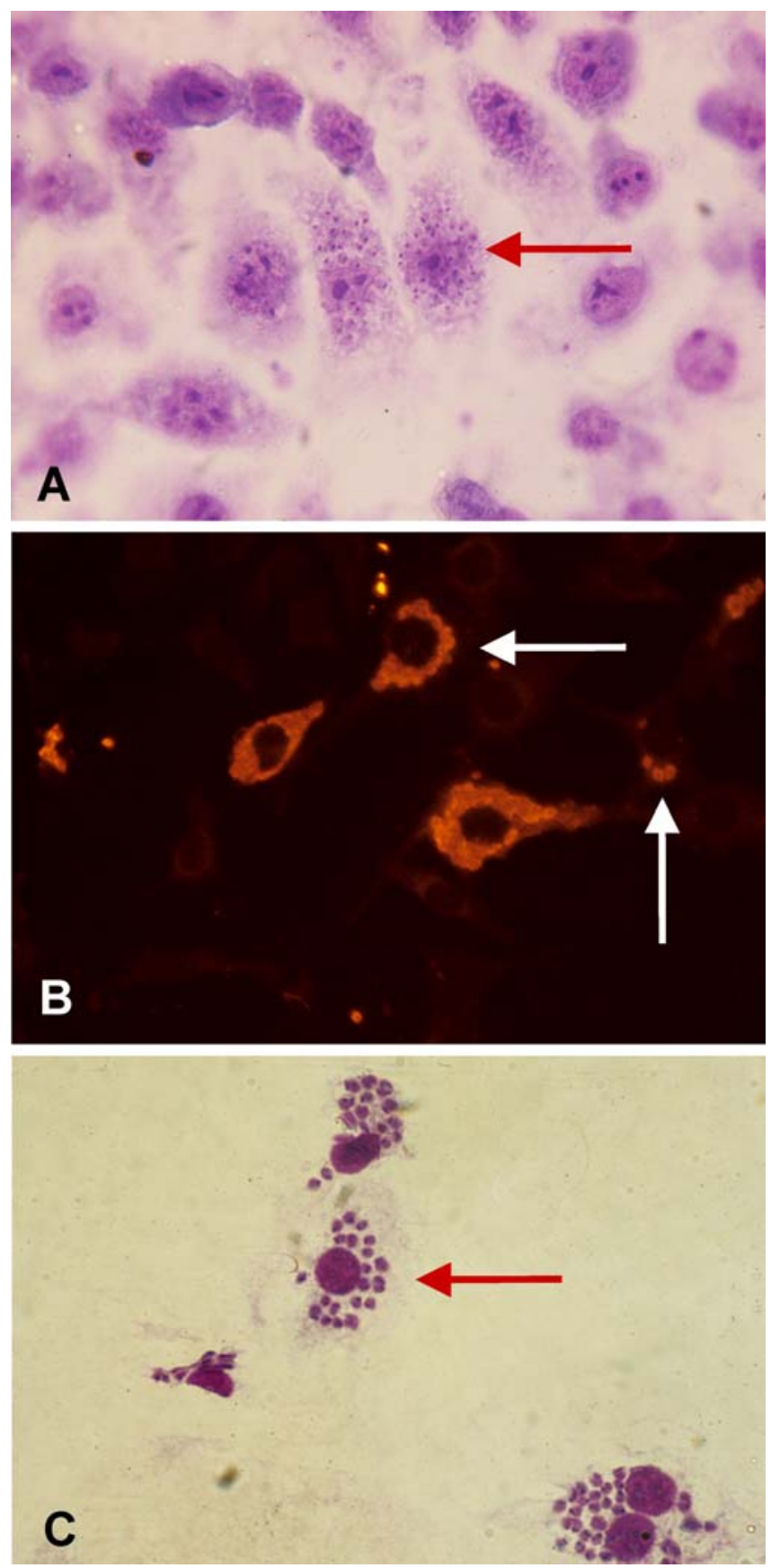

DOI: 10.1371/journal.ppat.0020062.g007

Figure 7. In Vitro Infection of Mouse Thymic Microenvironmental Cells by $T$. cruzi

The presence of the amastigote forms of the parasite within cultured thymic epithelial cells was ascertained by Giemsa staining (A) and by immunohistochemistry (B). Infected thymic phagocytic cells are shown in (C). Arrows indicate intracellular amastigote clusters. Pictures were kindly provided by Désio Aurélio Farias de Oliveira.

Conclusions and perspectives. The many aspects discussed above clearly illustrate that the thymus is a target organ in a variety of infectious diseases. The dynamic alterations in thymocyte subpopulations, including proliferation and death, the shaping of the $\mathrm{T}$ cell repertoire, and quantitative and qualitative migratory changes in thymocyte subpopulations, are likely related to events that take place later in the periphery of the immune system, thus influencing the pathophysiology of a given infection.

Although thymic atrophy is one common feature in a variety of infectious diseases, the mechanisms driving such thymocyte death apparently vary according to a given infection, and thus deserve detailed investigation.

Another important issue that needs to be further developed is the presence of a given infectious agent within the thymus versus the potential impact on the generation of the $\mathrm{T}$ cell repertoire, including tolerance to some peptides derived from the infectious organism.

In conclusion, more studies on the thymus in the context of infectious diseases are needed, to better understand the behavior of this organ in respect to thymocyte differentiation under the biological pressure of a given infection. These studies should address the generation of the $\mathrm{T}$ cell repertoire and potential autoimmune events (including cell death and cell expansion) and the export of cells toward the periphery. Such a systematic approach will certainly be helpful in improved design of specific immunotherapeutic interventions.

We should also consider attempts to enhance antigenspecific expansion of the thymus-derived repertoire through thymic vaccination with altered ligand peptides.

Furthermore, modulators of thymocyte migration and proliferation should be considered in order to yield larger numbers of antigen-specific $\mathrm{T}$ cells exiting the thymus and colonizing $\mathrm{T}$ cell regions of peripheral lymphoid organsprocedures that should result in the enhancement of the corresponding immunological response.

Lastly, the surprising (yet consistent) data unraveling a functional second thymus in the adult mouse [84] places on the stage a whole additional set of studies that should be carried out in order to see, at least in the mouse model, if a neck-located thymus is equally sensitive to the various infections discussed in this review.

\section{Acknowledgments}

We thank Dr. Liana Verinaud and Désio A. Farias-de-Oliveira for providing the pictures of intrathymic infection with $P$. brasiliensis and of in vitro infection and enhancement of ECM deposition in the thymus of T. cruzi infected mice, respectively. We are also grateful to Vinícius Cotta-de-Almeida and Daniella Areas Mendes-da-Cruz for allowing us to use their published results concerning thymocyte death and migration in murine T. cruzi infection, and to Leandra Linhares de Lacerda for help in retrieving the protein and nucleotide accession numbers displayed in Table 1 . W. Savino is the Brazilian coordinator of the Franco-Brazilian Associated Laboratory of Immunology.

Funding. This work was supported by grants from Fiocruz, CNPq, and Faperj.

Competing interests. The author has declared that no competing interests exist.

\section{References}

1. Res P, Spits H (1999) Developmental stages in the human thymus. Sem Immunol 11: 39-46.

2. Ritter MA, Palmer DB (1999) The human thymic microenvironment: New approaches to functional analysis. Sem Immunol 11: 13-21.

3. Savino W, Dardenne M (2000) Neuroendocrine control of thymus physiology. Endocrine Rev 21: 412-443.

4. Anderson G, Jenkinson EJ (2001) Lymphostromal interactions in thymic development and function. Nat Rev Immunol 1: 31-40.

5. Coutinho A, Caramalho I, Seixas E, Demengeot J (2005) Thymic commitment of regulatory $\mathrm{T}$ cells is a pathway of TCR-dependent selection that isolates repertoires undergoing positive or negative selection. Curr Topics Microbiol Immunol 293: 43-71. 
6. Maggi E, Cosmi L, Liotta F, Romagnani P, Romagnani S, et al. (2005) Thymic regulatory T cells. Autoimmun Rev 4: 579-586.

7. Sakaguchi S, Sakaguchi N (2005) Regulatory T cells in immunologic selftolerance and autoimmune disease. Int Rev Immunol 24: 211-226.

8. Dalmau SR, Freitas CS, Savino W (1999) High expression of fibronectin receptors and L-selectin as a hallmark of early steps of thymocyte differentiation: Lessons from sublethally irradiated mice. Blood 93: 974-990.

9. Savino W, Dalmau SR, Cotta-de-Almeida V (2000) Role of extracellular matrix mediated interactions in thymocyte migration. Dev Immunol 7: 19-28.

10. Annunziato F, Romagnani P, Cosmi L, Lazzeri E, Romagnani S (2001) Chemokines and lymphoiesis in the thymus. Trends Immunol 22: 277-281.

11. Savino W, Mendes-da-Cruz DA, Silva JS, Dardenne M, Cotta de Almeida V (2002) Intrathymic T cell migration: A combinatorial interplay of extracellular matrix and chemokines? Trends Immunol 23: 305-313.

12. Savino W, Mendes-Da-Cruz DA, Smaniotto S, Silva-Monteiro E, VillaVerde DM (2004) Molecular mechanisms governing thymocyte migration: Combined role of chemokines and extracellular matrix. J Leukocyte Biol 75: 951-961.

13. Ben-Efraim S, Keisari Y, Ophir R, Pecht M, Trainin N, et al. (1999) Immunopotentiating and immunotherapeutic effects of thymic hormones and factors with special emphasis on thymic humoral factor THF- $\gamma 2$. Crit Rev Immunol 19: 261-284.

14. Lannes Vieira J, van der Meide PH, Savino W (1991) Extracellular matrix components of the mouse thymus microenvironment. II. GammaInterferon modulates thymic epithelial cell proliferation and extracellular matrix production. Cell Immunol 137: 329-340.

15. Lagrota-Cândido JM, Vanderlei Jr FH, Villa Verde DMS, Savino W (1996) Exracellular matrix components of the mouse thymic microenvironment V. Interferon- $\gamma$ modulates thymocyte/thymic epithelial cell interactions via extracellular matrix ligands and receptors. Cell Immunol 170: 235-244

16. Villa-Verde DMS, Mello-Coelho V, Lagrota-Cândido JM, Savino W (1995) The thymic nurse cell complex: An in vitro model for extracellular matrixmediated intrathymic T cell migration. Braz J Med Biol Res 28: 907-912.

17. Savino W, Dardenne M, Marche C, Trophylme D, Dupui JM, et al. (1986) Thymic epithelium in AIDS: An immunohistologic study. Am J Pathol 122 302-307.

18. Sodora DL, Milush JM, Ware F, Wozniakowski A, Montgomery L, et al. (2002) Decreased levels of recent thymic emigrants in peripheral blood of simian immunodeficiency virus-infected macaques correlates with alterations within the thymus. J Virol 76: 9981-9990.

19. Suzuki H, Motohara M, Miyake A, Ibuki K, Fukazawa Y, et al. (2005) Intrathymic effect of acute pathogenic SHIV infection on T-lineage cells in newborn macaques. Microbiol Immunol 49: 667-679.

20. Markovistz R, Bertho AL, Matos DC (1994) Relationship between apoptosis and thymocyte depletion in rabies-infected mice. Braz J Med Biol Res 27 $1599-1603$

21. Gibb TR, Bray M, Geisbert TW, Steele KE, Kell WM, et al. (2001) Pathogenesis of experimental Ebola Zaire virus infection in BALB/c mice. J Comp Pathol 125: 233-242.

22. Godfraind C, Holmes KV, Coutelier JP (1995) Thymus involution induced by mouse hepatitis virus A59 in BALB/c mice. J Virol 69: 6541-6547.

23. Price P, Olver SD, Silich M, Nador TZ, Yerkovich S, et al. (1996) Adrenalitis and the adrenocortical response of resistant and susceptible mice to acute murine cytomegalovirus infection. Eur J Clin Invest 26: 811-819.

24. Ito M, Nishiyama K, Hyodo S, Shigeta S, Ito T (1985) Weight reduction of thymus and depletion of lymphocytes of T-dependent areas in peripheral lymphoid tissues of mice infected with Francisella tularensis. Infect Immun. 49: 812-818.

25. Chen W, Kuolee R, Austin JW, Shen H, Che Y, et al. (2005) Low dose aerosol infection of mice with virulent type A Francisella tularensis induces severe thymus atrophy and $\mathrm{CD} 4^{+} \mathrm{CD} 8^{+}$thymocyte depletion. Microb Pathog 39: 189-196.

26. Watson SR, Redington TJ, Miller TB, Bullock WE (1984) Flow microfluorometry analysis of alterations in T-lymphocyte subsets during murine listeriosis. Infect Immun 45: 372-377.

27. Savino W, Leite de Moraes MC, Hontebeyrie-Joskowicz M, Dardenne M (1989) Studies on the thymus in Chagas' disease. I. Changes in the thymic microenvironment in mice acutely infected with Trypanosoma cruzi. Eur J Immunol 19: 1727-1733.

28. Leite de Moraes MC, Hontebeyrie-Joskowicz M, Leboulanger F, Savino W, Dardenne M, et al. (1991) Studies on the thymus in Chagas' disease. II. Thymocyte subset fluctuations in Trypanosoma cruzi-infected mice: Relationship to stress. Scand J Immunol 33: 267-275.

29. Leite de Moraes MC, Hontebeyrie-Joskowicz M, Dardenne M, Savino W (1992) Modulation of thymocyte subsets during acute and chronic phases of experimental Trypanosoma cruzi infection. Immunology 77: 95-98.

30. Seixas E, Ostler D (2005) Plasmodium chabaudi chabaudi (AS): Differential cellular responses to infection in resistant and susceptible mice. Exp Parasitol 110: 394-405.

31. Wellhausen SM, Boros DV (1982) Atrophy of the thymic cortex in mice with granulomatous schistosomiasis mansoni. Infect Immun 35: 1063-1069.

32. Savino W, Leite de Moraes MC, Silva Barbosa SD, Fonseca EC, Cotta de Almeida V, et al. (1992) Is the thymus a target organ in infectious diseases? Mem Inst Oswaldo Cruz (Rio de Janeiro) 87: 73-78.
33. Ljungstrom I, Huldt G (1977) Effect of experimental trichinosis on unrelated humoral and cell mediated immunity. Acta Pathol Microbiol Scand [C] 85: 131-141.

34. Brito VN, Souto PC, Cruz-Hofling MA, Ricci LC, Verinaud L (2002) Thymic invasion and atrophy induced by Paracoccidioides brasiliensis in BALB/c mice. Med Mycol 41: 1-5.

35. Souto PCS, Brito VN, Gameiro J, Cruz-Hofling MA, Verinaud L (2003) Programmed cell death in thymus during experimental paracoccidioidomycosis. Med Microbiol Immunol 192: 225-229.

36. Watson SR, Miller TB, Redington TJ, Bullock WE (1983) Immunoregulation in experimental disseminated histoplasmosis: Flow microfluorometry (FMF) studies of the Thy and Lyt phenotypes of T lymphocytes from infected mice. J Immunol 131: 984-990.

37. Herold MJ, McPherson KG, Reichardt HM (2006) Glucocorticoids in T cell apoptosis and function. Cell Mol Life Sci 63: 60-72.

38. Wang D, Müller N, McPherson KG, Reichardt HM (2006) Glucocorticoids engage different signal transduction pathways to induce apoptosis in thymocytes and mature T cells. J Immunol 176: 1695-1702.

39. Van der Brandt J, Wang D, Reichardt HM (2004) Resistance of singlepositive thymocytes to glucocorticoid-induced apoptosis is mediated by CD28 signaling. Mol Endocrinol 18: 687-695.

40. Cardenas-Palomo LF, de Souza-Matos DC, Chaves-Leal E, Bertho AL, Marcovistz R (1995) Lymphocyte subsets and cell proliferation analysis in rabies-infected mice. J Clin Lab Immunol 46: 49-61.

41. Perry LL, Hotchkiss JD, Lodmell DL (1990) Murine susceptibility to street rabies virus is unrelated to induction of host lymphoid depletion. J Immunol 144: 3552-3557.

42. Corrêa-de-Santana E, Paez-Pereda M, Theodoropoulou M, Gruebler Y, Nihei OK, et al. (2006) Hypothalamus-pituitary-adrenal axis during Trypanosoma cruzi acute infection in mice. J Neuroimmunol 173: 12-22.

43. Jondal M, Pazirandeh A, Okret S (2004) Different roles for glucocorticoids in thymocyte homeostasis? Trends Immunol 25: 595-600.

44. Cole TJ, Liddicoat DR, Godfrey DI (2005) Intrathymic glucocorticoid production and thymocyte survival: another piece in the puzzle. Endocrinology 146: 2499-2500.

45. Rivera MT, Marques-de-Araujo S, Lucas R, Deman J, Truyens C, et al (1995) High tumor necrosis factor- $\alpha$ production in Trypanosoma cruziinfected pregnant mice and increased TNF- $\alpha$ gene transcription in their offspring. Infect Immun 63: 591-595.

46. De Meis J, Mendes-da-Cruz DA, Farias-de-Oliveira DA, Correa-de-Santana E, Pinto-Mariz F, et al. (2006) Atrophy of mesenteric lymph nodes in experimental Chagas' disease: Differential role of Fas/Fas-L and TNFR1/ TNF pathways. Microbes Infect 8: 221-231.

47. Henriques-Pons A, De Meis J, Cotta-de-Almeida V, Savino W, Araújo-orge TC (2004) Fas and perforin are not required for thymus atrophy induced by Trypanosoma cruzi infection. Exp Parasitol 107: 1-4.

48. Verinaud L, Cruz-Höfling MA, Sakurada JK, Rangel HA, Vassallo J, et al. (1998) Immunodepression induced by Trypanosoma cruzi and mouse hepatitis type 3 virus is associated with thymic apoptosis. Clin Diag Lab Immunol 5: 186-191.

49. Olivieri BP, Farias-de-Oliveira DA, Araújo-Jorge TC, Cotta-de-Almeida V (2005) Benznidazole therapy in Trypanosoma cruzi-infected mice blocks thymic involution and apoptosis of $\mathrm{CD} 4^{+} \mathrm{CD} 8^{+}$double-positive thymocytes. Antimicrob Agents Chemother 49: 1981-1987.

50. Mucci J, Hidalgo A, Mocetti E, Argibay PF, Leguizamon MS, et al. (2002) Thymocyte depletion in Trypanosoma cruzi infection is mediated by transsialidase-induced apoptosis on nurse cell complex. Proc Natl Acad Sci USA 99: 3896-3901.

51. Mantuano-Barradas M, Henriques-Pons A, Araújo-orge TC, Di Virgílio F, Coutinho-Silva R, et al. (2003) Extracellular ATP induces cell death in $\mathrm{CD} 4^{+} / \mathrm{CD} 8^{+}$thymocytes in mice infected with Trypanosoma cruzi. Microbes Infect 5: 1363-1371.

52. Villa-Verde DMS, Silva-Monteiro E, Jasiulionis M, Farias-de-Oliveira DA, Brentani RR, et al. (2002) Galectin-3 modulates carbohydrate dependent thymocyte interactions with the thymic microenvironment. Eur J Immunol 32: 1434-1344.

53. Goncalves da Costa SC, Calabrese KS, Bauer PG, Savino W, Lagrange PH (1991) Studies on the thymus in Chagas disease. III. Colonization of the thymus and other lymphoid organs from adult and newborn mice by Trypanosoma cruzi. Pathol Biol 39: 91-97.

54. Leite de Moraes MC, Minoprio P, Dy M, Dardenne M, Savino W, et al. (1994) Endogenous IL-10 and IFN- $\gamma$ production controls thymic cell proliferation in mice acutely infected by Trypanosoma cruzi. Scand J Immunol 39: 51-58

55. Koka PS, Brooks DG, Razai A, Kitchen CM, Zack JA, et al. (2003) HIV type I infection alters cytokine mRNA expression in thymus. AIDS Res Human Retroviruses 19: 1-12.

56. Valentin H, Azocar O, Horvat B, Williems R, Garrone R (1999) Measles virus infection induces terminal differentiation of human thymic epithelial cells. J Virol 73: 2212-2221.

57. Dardenne M, Bach JF, Safai B (1983) Low serum thymic hormone levels in patients with acquired immunodeficiency syndrome. N Engl J Med 309: 48-49.

58. Incefy GS, Pahwa S, Pahwa R, Sarngadharan MG, Menez R, et al. (1986) Low circulating thymulin-like activity in children with AIDS and AIDSrelated complex. AIDS Res 2: 109-116. 
59. Rothe M, Chêne L, Nugeyre N, Barré-Sinoussi F, Israël N (1998) contact with thymic epithelial cells as a prerequisite for cytokines enhanced HIV-1 replication in thymocytes. J Virol 72: 5852-5861.

60. Schmitt N, Chêne L, Boutolleau D, Nugeyre M-T, Guillemard EG, et al (2003) Positive regulation of CXCR4 expression and signaling by interleukin- 7 in $\mathrm{CD}^{+}$thymocytes correlates with their capacity to favor human immunodeficiency X4 virus replication. J Virol 77: 5784-5793.

61. Mendes-da-Cruz DA, Silva JS, Cotta-de-Almeida V, Savino W (2006) Altered thymocyte migration during experimental acute Trypanosoma cruz infection: Combined role of fibronectin and the chemokines CXCL12 and CCL4. Eur J Immunol 36: 1486-1493.

62. Cotta-de-Almeida V, Bertho AL, Villa-Verde DMS, Savino W (1997) Phenotypic and functional analysis of thymic nurse cells following acute Trypanosoma cruzi infection. Clin Immunol Immunopathol 82: 125-132.

63. Cotta-de-Almeida V, Mendes-da-Cruz DA, Bonomo A, Savino W (2003) Acute Trypanosoma cruzi infection modulates intrathymic contents of extracellular matrix ligands and receptors and alters thymocyte migration. Eur J Immunol 33: 2439-2448.

64. Mendes-da-Cruz DA, de Meis J, Cotta-de-Almeida V, Savino W (2003) Experimental Trypanosoma cruzi infection alters the shaping of the central and peripheral T cell repertoire. Microbes Infect 5: 825-832.

65. Roffe E, Silva AA, Marino AP, dos Santos PV, Lannes-Vieira J (2003) Essential role of VLA-4/VCAM-1 pathway in the establishment of CD8 ${ }^{+} \mathrm{T}$ cell-mediated Trypanosoma cruzi-elicited meningoencephalitis. J Neuroimmunol 142: 17-30.

66. Michailowsky V, Celes MR, Marino AP, Silva AA, Vieira LQ, et al. (2004) Intercellular adhesion molecule 1 deficiency leads to impaired recruitment of T lymphocytes and enhanced host susceptibility to infection with Trypanosoma cruzi. J Immunol 173: 463-470.

67. Machado FS, Koyama NS, Carregaro V, Ferreira BR, Milanezi CM, et al. (2005) CCR5 plays a critical role in the development of myocarditis and host protection in mice infected with Trypanosoma cruzi. J Infect Dis 191: 627-636

68. Ribeiro-dos-Santos R, Laus JL, Silva JS, Savino W, Rossi M, et al. (1992) Anti-CD4 abrogates rejection and reestablishes long-term tolerance to syngeneic newborn hearts grafted in mice chronically infected with Trypanosoma cruzi. J Exp Med 175: 29-39.

69. Silva Barbosa SD, Cotta-de-Almeida V, Riederer I, Dardenne M, Bonomo $\mathrm{AC}$, et al. (1997) Involvement of laminin and its receptor upon syngeneic heart graft rejection by $\mathrm{CD} 4^{+}$autoreactive lymphocytes derived from Trypanosoma cruzi chronically-infected mice. J Immunol 159: 997-1003.

70. Douek D, Betts MR, Hill BJ, Little SJ, Lempicki R, et al. (2001) Evidence for increased T cell turnover and decreased thymic output in HIV infection. J Immunol 167: 6663-6668.

71. Diaz M, Douek DC, Valdez H, Hill BJ, Peterson D, et al. (2003) T cells containing $\mathrm{T}$ cell receptor excicion circles are inversely related to HIV replication and are selectively and rapidly released into circulation with antiretroviral treatment. AIDS 17: 1145-1149.

72. Napolitano LA, Lo JC, Gotway MB, Mulligan K, Barbour JD, et al. (2002) Increased thymic mass and circulating naive CD4 T cells in HIV-1-infected adults treated with growth hormone. AIDS 16: 1103-1111.
73. Teixeira L, Valdez H, McCune JM, Koup RA, Badley AD, et al. (2001) Poor CD4 $\mathrm{T}$ cell restoration after suppression of HIV-1 replication may reflect lower thymic function. AIDS 15: 1749-1756.

74. Lee JC, Boechat MI, Belzer M, Church JA, De Ville J, et al. (2006) Thymic volume, T-cell populations, and parameters of thymopoiesis in adolescent and adult survivors of HIV infection acquired in infancy. AIDS 20: 667-674.

75. Choe EY, Schoenberger ES, Groopman JE, Park I-W (2002) HIV nef inhibits T cell migration. J Biol Chem 48: 64079-46084.

76. Permar SR, Moss WJ, Ryon JJ, Douek DC, Monze M, et al. (2003) Increased thymic output during acute measles virus infection. J Virol 77: 7872-7879.

77. Savino W, Silva JS, Silva-Barbosa SD, Dardenne M, Ribeiro dos Santos R (1990) Anti-thymic cell autoantibodies in human and murine chronic Chagas disease. EOS J Immunol Immunopharmacol 10: 204-205.

78. Grody WW, Fligiel S, Naeim F (1985) Thymus involution in the acquired immunodeficiency syndrome. Am J Clin Pathol 84: 85-95.

79. Wang Z, Horowitz HW, Orlikowsky T, Hahn BI, Trejo V, et al. (1999) Polyspecific self-reactive antibodies in individuals infected with human immunodeficiency virus facilitate $\mathrm{T}$ cell deletion and inhibit $\mathrm{co}^{-}$ stimulatory accessory cell function. J Infect Dis 180: 1072-1079.

80. Laine D, Trescol-Biémont MC, Songhi S, Libeau G, Marie JC, et al. (2003) Measles virus (MV) nucleoprotein binds to a novel surface receptor distinct from FC $\gamma \mathrm{RII}$ via its C-terminal domain: Role in MV-induced immunosuppression. J Virol 77: 11322-11346.

81. Schmitt N, Nugeyre MT, Scott-Algara D, Cumont MC, Barre-Sinoussi F, et al. (2006) Differential susceptibility of human thymic dendritic cell subsets to X4 and R5 HIV-1 infection. AIDS 20: 533-542.

82. Fridkis-Valery M, Reche PA, Reinherz E (2004) Peptide variants of viral CTL epitopes mediate positive selection and emigration of Ag-specific thymocytes in vivo. J Immunol 173: 1140-1150.

83. Fridkis-Valery M, Reinherz E (2004) New approaches to eliciting protective immunity through $\mathrm{T}$ cell repertoire manipulation: The concept of thymic vaccnation. Med Immunol 3: 1-10

84. Terszowski G, Müller S, Bleul CC, Blum C, Schirmbeck R, et al. (2006) Evidence for a functional second thymus in mice. Science 312: 206-207.

85. Lafon M, Scott-Algara D, Marche PN, Cazenave PA, Jouvin-Marche E (1994) Neonatal deletion and selective expansion of mouse $\mathrm{T}$ cells by exposure to rabies virus nucleocapsid superantigen. J Exp Med 180: 1207-1215.

86. Auwaerter PG, Kaneshima H, McCune JM, Wiegand G, Griffin DE (1996) Virus measles infection of the thymic epithelium in the SCID-hu mice lead to thymocyte apoptosis. J Virol 70: 3734-3740.

87. Vidalain PO, Laine D, Zaffran Y, Azocar O, Servet-Delprat C, et al. (2002) Interferons mediate terminal differentiation of human cortical thymic epithelial cells. J Virol 76: 6415-6424.

88. Takeuchi K, Takeda M, Miyajima N, Ami Y, Nagata N, et al. (2005) Stringent requirement for the $\mathrm{C}$ protein of wild-type measles virus for growth both in vitro and in macaques. J Virol 79: 7838-7844.

89. Peters M, Wagner F, Schares G (2000) Canine neosporosis: Clinical and pathological findings and first isolation of Neospora caninum in Germany. Parasitol Res 86: 1-6.

90. Savino W (1990) The thymic microenvironment in infectious diseases. Mem Inst Oswaldo Cruz (Rio de Janeiro) 85: 255-260. 